Research Article

\title{
Corrosion Risk of Reinforced Concrete Structure Arising from Internal and External Chloride
}

\author{
M. J. Kim and K. Y. Ann (iD \\ Department of Civil and Environmental Engineering, Hanyang University, Ansan 426, Republic of Korea \\ Correspondence should be addressed to K. Y. Ann; kann@hanyang.ac.kr
}

Received 12 January 2018; Revised 9 March 2018; Accepted 25 March 2018; Published 12 April 2018

Academic Editor: Ana S. Guimarães

Copyright ( 2018 M. J. Kim and K. Y. Ann. This is an open access article distributed under the Creative Commons Attribution License, which permits unrestricted use, distribution, and reproduction in any medium, provided the original work is properly cited.

\begin{abstract}
The corrosion risk of internal chloride and external chloride from three different exposure conditions was evaluated. The initiation of corrosion was detected by monitoring the galvanic current between cathode metal and embedded steel. The chloride threshold was determined by measuring the corrosion rate of steel by the polarization technique for internal chloride and the chloride profiling test for external chloride. As the result, the initiation of corrosion was accelerated with a cyclic wet/dry condition, compared to the totally wet condition. In addition, it was found that an increase of the drying ratio in the exposure condition resulted in an increase of corrosion rate after initiation. The threshold level of external chloride ranged from 0.2 to $0.3 \%$ weight by cement and internal chloride shows higher range, equated to $1.59-3.10 \%$. Based on these data, the chloride penetration with exposure condition was predicted to determine the service life of reinforced concrete structure.
\end{abstract}

\section{Introduction}

There is a general agreement that embedded steel in concrete forms a passive film on the surface and protects the steel against corrosion. The passive film is preserved by high alkalinity in concrete; however, breakdown of passive film occurs when the concentration of chloride at the vicinity of steel exceeds the chloride threshold level (CTL) [1]. Owing to this problem, various studies have been carried out to predict chloride transport according to exposure conditions because precise prediction of chloride transport leads to an enhancement of the accuracy of life cycle prediction. The determination of the CTL is another crucial factor influencing on the service life prediction [2]. It is known that the CTL changes with various conditions, such as chloride source, exposure condition, and mixing materials; however, the CTL used in service life prediction is conservative, accounting for $0.2-0.4 \%$ by weight of cements $[3,4]$. The main reason for this may be attributed to the absence of exact test methods for defining the CTL, of which the complexity moreover depends on the test methods. In previous studies, due to the convenience of experiment and time-saving, several experiments were conducted to determine the CTL with the steel directly immersed in solution $[5,6]$ or with admixed chloride [7-9]. In the case of the solution test, the results show that the corrosion of steel initiated in a small amount of chloride, which seems to be unrealistic in that it did not consider the corrosion resistance of concrete. For the chloride admixed test, the CTL varied from 0.1 to $1.0 \%$ by weight of the binder; however, it could not fully cover the real condition of reinforced concrete structure exposed to chloride environment. Experiments with external chloride were also conducted with long-time immersed specimens, but considering diverse exposure condition is deficient [10-12]. Hence, it is necessary to define the CTL depending on the chloride sources and consequently to evaluate the corrosion risk of reinforced concrete structure.

The present study discussed about the corrosion risk and CTL for both internal chloride and external chloride. The influence of internal chloride was evaluated by measuring the corrosion current density for 100 days by the polarization technique. For external chloride, the initiation of corrosion with three different exposure conditions was detected by monitoring the galvanic current, and then, the chloride 
penetration rate was evaluated to determine the CTL. Subsequently, the CTL was applied to the service life prediction to evaluate the corrosion resistance of the structure.

\section{Experimental Work}

In this paper, corrosion initiation induced by internal chloride and external chloride was evaluated. For the experiments, mortar specimens were made to reduce the size while considering the influence of the aggregate in the corrosion process. The mix proportion was $1.00: 4.00: 2.46$ for ordinary Portland cement, deionized water, and sand (maximum size was $15 \mathrm{~mm}$ ). The experimental details for both internal/external chloride specimens and corrosion measuring method are stated as follows.

2.1. Chloride Admixed Specimens. Six levels of chloride were admixed in mixing water as $\mathrm{NaCl}: 0.2,0.5,1.0,1.5,2.0$, and $3.0 \%$ by weight of cement. The mortar specimens were cast in a cylinder mould $(\varnothing 40 \times 80 \mathrm{~mm})$ with a smooth steel rebar $(\varnothing 10 \times 80 \mathrm{~mm})$ placed in the center of the specimen. In the process of demoulding, the cement paste $(0.25$ of $w / c$ ratio) was covered on the end of the steel bars to ensure the protection of corrosion at the exposed part. After then, an epoxy resin was coated at the top and bottom so that ions and current can pass only through the sides. To achieve enough hydration degree and high relative humidity in a pore matrix, the specimens were cured for 28 days in a controlled chamber at $25 \pm 1^{\circ} \mathrm{C}$ and $95 \pm 2 \%$ relative humidity. This curing condition was equally applied to external chloride specimens. After 28 days of curing, the corrosion current density of embedded steel was monitored by the polarization technique.

2.2. Immersed Specimens. Profile specimens and corrosion test specimens were prepared separately to detect the corrosion initiation of steel and determine the CTL. The same cylindrical mortar specimens $(\varnothing 40 \times 80 \mathrm{~mm})$ containing a smooth steel rebar $(\varnothing 10 \times 80 \mathrm{~mm})$ were fabricated for corrosion measurement, without any admixed chloride. For the chloride profile test, a mortar disc $(\varnothing 100 \times 50 \mathrm{~mm})$ was cast and coated, immediately after demoulding, by epoxy resin except the top of the specimen to drive onedimensional chloride transport. All the specimens were cured in a chamber for 28 days and then exposed to the chloride. Considering the tidal environment, it was classified into three types of exposure condition, that is, 2 days of wetting (immersed)/8 days of drying (to which will be referred as $2 w / 8 d), 5$ days of wetting/ 5 days of drying ( $5 w / 5 d)$, and totally immersed (10w). At the immersion stage, the specimens were kept in $1 \mathrm{M} \mathrm{NaCl}$ solution at $25 \pm 2^{\circ} \mathrm{C}$ of ambient temperature and stored in a chamber under the dry condition $\left(25 \pm 1^{\circ} \mathrm{C}\right.$ and $30 \%$ related humidity). The galvanic current of the embedded steel was measured every 10 days to observe the corrosion initiation.

2.3. Chloride Profile. The chloride profile was obtained from the dust samples collected by grinding the mortar surface in
$5.0 \mathrm{~mm}$ depth increments to $30.0 \mathrm{~mm}$. The free chloride in each sample was extracted by stirring for 5 minutes in a $50^{\circ} \mathrm{C}$ of deionized water and measured by chloride ion-selective electrode manufactured from Orion ${ }^{\mathrm{TM}}$. To determine the surface chloride concentration and diffusion coefficient, the measured chloride concentration data were used to solve Fick's second law of diffusion. Fick's second law in a semiinfinite space is represented as follows:

$$
\frac{C(x, t)}{C_{\mathrm{s}}}=\operatorname{erf}\left[\frac{x}{2 \sqrt{D t}}\right],
$$

where $C(x, t)$ is the chloride concentration at depth $x$ after time $t(\mathrm{~s}), C_{\mathrm{s}}$ is the surface chloride concentration $\left(\% / \mathrm{m}^{3}\right), D$ is the apparent diffusion coefficient $\left(\mathrm{m}^{2} / \mathrm{s}\right), x$ is the depth from the surface $(\mathrm{m})$, and $t$ is the time of exposure (s). To determine the CTL of immersed specimens, the profile data were obtained at the time when the corrosion initiation was detected by the galvanic current test.

2.4. Corrosion Measurement. The corrosion initiation was detected by measuring the current flow between the embedded steel and cathode metal (titanium mesh). The specimens were placed with a cylindrical titanium mesh in $1 \mathrm{M}$ sodium hydroxide solution (Figure 1(a)). Although galvanic current measurements did not reveal the quantitative corrosion rate, it is possible to deduce the time of corrosion initiation through the time when the current increases sharply. The galvanic current was determined by calculating the measured potential difference across $10 \mathrm{k} \Omega$ resistor, using Ohm's law.

Linear polarization resistance (LPR) measurement was conducted to observe the corrosion current of steel. The schematic diagram of the electrical circuit of the polarization technique is shown in Figure 1(b). The mortar specimen was immersed in $1 \mathrm{M}$ sodium hydroxide solution, and two electrodes (counter and reference electrodes) were arranged and connected with the instrument in the solution. The standard saturated calomel electrode (SCE) and carbon electrode were used as the reference electrode and counter electrode, respectively. Reference 600 from Gamry Instrument was used as the potentiostat. The LPR measurements were performed by applying a potential signal ranged from $\pm 20 \mathrm{mV}$ about $E_{\text {corr }}$ at $0.2 \mathrm{mV} / \mathrm{s}$ of the scan rate and measuring the current response. Then, the corrosion current was calculated by the equation as follows:

$$
\begin{gathered}
R_{\mathrm{p}}=\frac{\Delta E}{\Delta I}, \\
I_{\text {corr }}=\frac{B}{R_{\mathrm{p}}},
\end{gathered}
$$

where $R_{\mathrm{p}}$ is the polarization resistance $(\Omega), \Delta E$ is the change in potential $(\mathrm{V}), \Delta I$ is the change in current $(\mathrm{A}), I_{\text {corr }}$ is the corrosion current (A), and $B$ is the Stern-Geary constant. The Stern-Geary constant should be determined empirically; however, it was generally assumed to be $26 \mathrm{mV}$ for active and $52 \mathrm{mV}$ for passive state of steel [13]. $I_{\text {corr }}$ was converted to the corrosion rate to surface area of the steel rebar. 


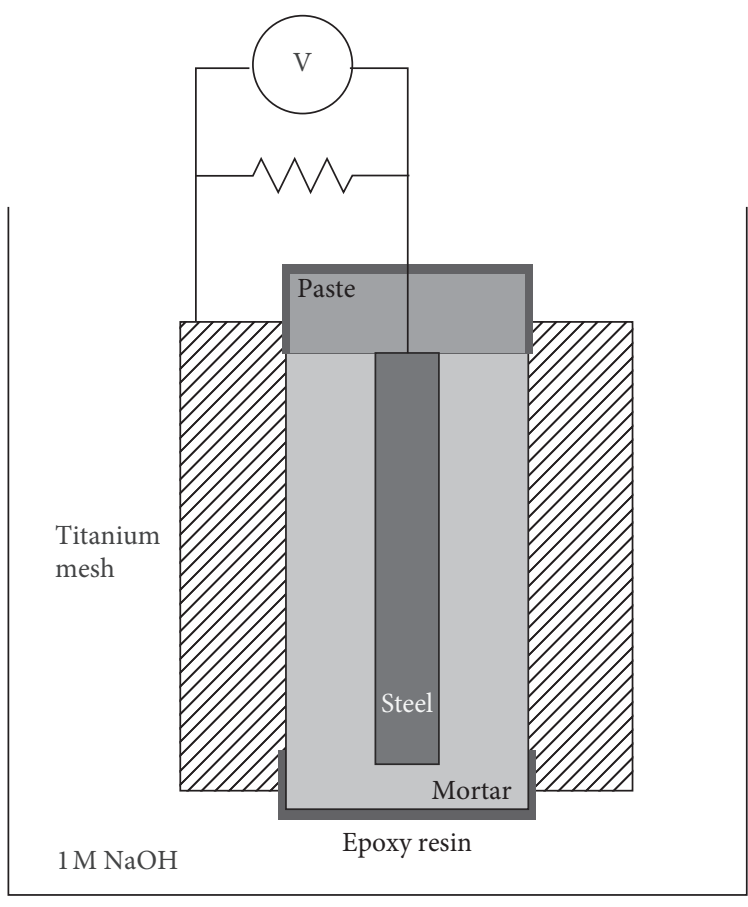

(a)

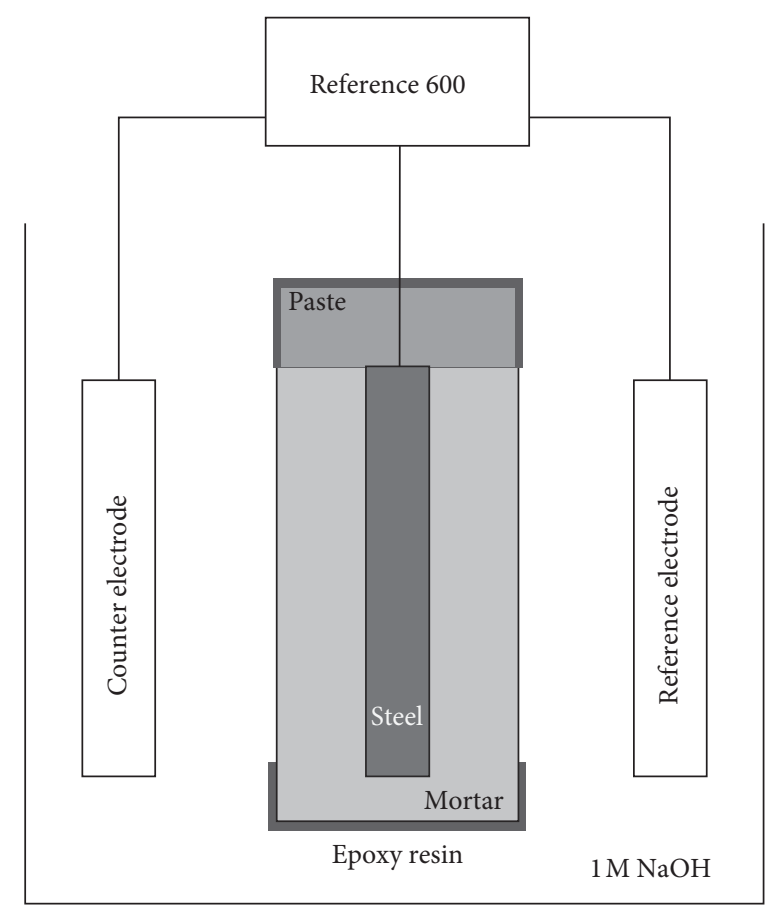

(b)

FIGURE 1: Schematic of the experimental setup of (a) galvanic cell monitoring and (b) LPR measurement.

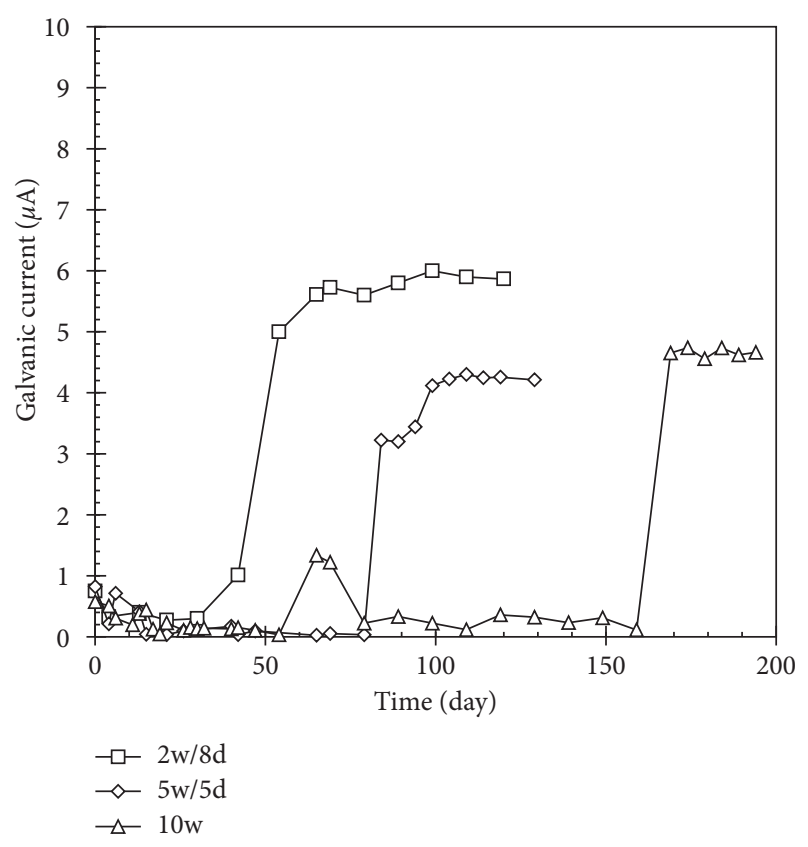

Figure 2: Galvanic current monitoring with different wet time proportions.

\section{Result and Discussion}

3.1. Corrosion Initiation. The corrosion initiation of steel in mortar, exposed to different exposure conditions, was determined by monitoring the galvanic current, as shown in Figure 2. At the beginning of the monitoring, a relatively low galvanic current value appeared, irrespective of the exposure condition. This convinced that the steel in the mortar specimen was free from corrosion (passivated). The corrosion initiation time was varied depending on the exposure condition. The $2 \mathrm{w} / 8 \mathrm{~d}$ specimen indicated no remarkable change until 40 days and subsequently increased up to about $6 \mu \mathrm{A}$. The increased current remained steadily thereafter. $5 \mathrm{w} / 5 \mathrm{~d}$ and $10 \mathrm{w}$ specimens showed a sharp increase of current at 90 and 160 days, respectively. And the current of the $10 \mathrm{w}$ specimen was increased up to $1.3 \mu \mathrm{A}$ at 60 days and then was decreased at 80 days. This result could be supposed as an initiation of localized corrosion and repassivation, though the interpretation of repassivation in galvanic current measurement is still controversial.

Figure 3 shows the changes in the corrosion current density of embedded steel, derived by LPR measurement. According to the previous studies, corrosion current density over $0.1 \mu \mathrm{A} / \mathrm{cm}^{2}$ was identified as the depassivation of steel $[14,15]$. Compared with the galvanic current test results, the corrosion of steel in mortar, subjected to different exposure conditions, initiated at similar or later time. For example, the $2 \mathrm{w} / 8 \mathrm{~d}$ specimen showed a corrosion current density value higher than $0.1 \mu \mathrm{A} / \mathrm{cm}^{2}$ after 60 days and gradually increased after that. The $5 \mathrm{w} / 5 \mathrm{~d}$ specimen required 90 days to exceed $0.1 \mu \mathrm{A} / \mathrm{cm}^{2}$ and 170 days for the $10 \mathrm{w}$ specimen. After 300 days, the current density of each specimen was converged to a constant value, accounting for $30,8.0$, and $0.5 \mu \mathrm{A} / \mathrm{cm}^{2}$ for $2 \mathrm{w} / 8 \mathrm{~d}, 5 \mathrm{w} / \mathrm{d}$, and $10 \mathrm{w}$ specimens, respectively. It is presumed that the higher corrosion current density of steel, resulting from cyclic wetting and drying exposure conditions, is due to the higher penetration rate of both chloride and oxygen [16]. Thus, it is evident that high drying ratio accelerates the corrosion initiation time and increases the 


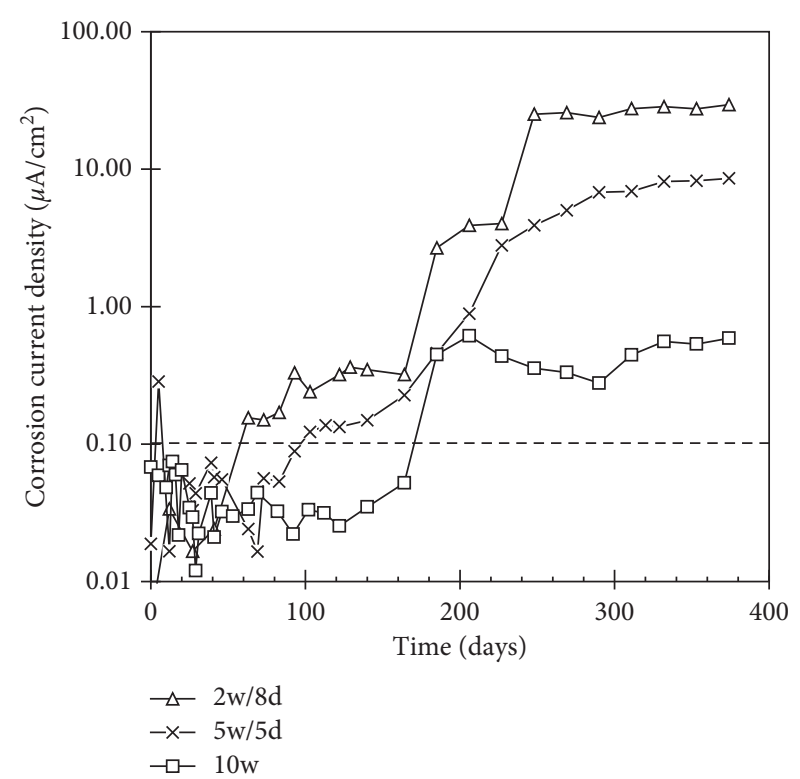

FIgURE 3: Changes in corrosion current density of the specimen exposed to the external chloride.

corrosion current density in the corrosion propagation phase. This acceleration of corrosion, consequently, may cause a hazardous defect on the marine-reinforced structure, especially exposed to high tide level. Thus, a totally immersed condition imposes a higher CTL of concrete than that exposed to a cyclic wet/dry condition.

3.2. Chloride Threshold Level. To evaluate the influence of internal chloride on the corrosion rate, the corrosion current density was monitored for 100 days. The average corrosion current density was obtained by integrating the measured current density and dividing it by the total number of days to measure. The average corrosion current density of the steel bar in the mortar specimen as a function of the concentration of admixed chloride (total chloride) is depicted in Figure 4. The average corrosion current density showed exponential increase in total chloride. The CTL ranged from $1.74-2.46 \%$ of the total chloride content for $0.1-0.2 \mu \mathrm{A} / \mathrm{cm}^{2}$. From the prior research, Alonso et al. [14] show a similar CTL ranged from 1.24 to 3.08, and Hope and Ip [8] reported relatively low CTL ranged from 0.92 to 1.35 . However, the CTL prescribed by the British Standard or ACI is 0.4 or $0.2 \%$ by the weight of cement, and it is significantly lower than this result $[17,18]$. This difference may be due to the variation of chloride binding capacity arising from chloride source. In pore solution, free chloride chemically reacted with the hydration products of $\mathrm{C}_{3} \mathrm{~A}$ or $\mathrm{C}_{4} \mathrm{AF}$ into Friedel's salt at the early hydration process. The formation of Friedel's salt could remove the free chloride in the pore solution, which participates in the corrosion process. In fact, the formation of Friedel's salt reduced in the external chloride condition since the chloride penetrates after hydration of the cement proceeds $[19,20]$. From a literature review on real structures, the CTL was moreover produced in a wide range, accounting for about $0.2-1.5 \%$, presumably due to environmental influencing factors to corrosiveness of steel,

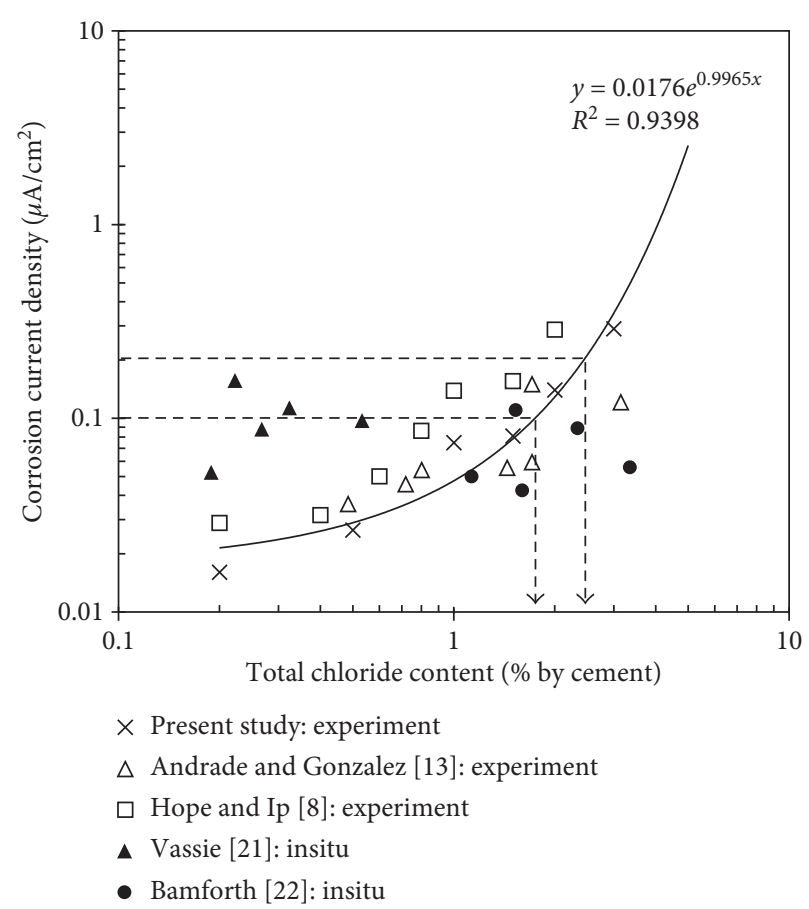

FIGURE 4: Changes in corrosion current density of the specimen with chloride in cast.

such as relative humidity, moisture level in concrete, and temperature $[21,22]$. Thus, it seems very difficult to empirically determine the CTL from real structures, with no adjustment of environmental factors.

The chloride profile with different exposure conditions was conducted at the time when the corrosion initiation was observed (at 40, 90, and 160 days), as shown in Figures 5(a)-5(c). The calculated surface chloride and apparent diffusion coefficient are stated in Table 1 . It was found that an increase in the drying ratio resulted in an increase of the total penetrated chloride concentration through all depths from the surface. When the specimen is exposed to dry conditions, the water saturation in the pore decreases and, therefore, the chloride transport is dominated by both diffusion and absorption, particularly at the outer section. Therefore, as the transportation rate of chloride ions induced by absorption is generally higher than diffusion, the $2 \mathrm{w} / 8 \mathrm{~d}$ specimen shows the highest amount of chloride penetration throughout the depth from the exposed surface. Liam et al. and TWRL $[23,24]$ reported the rapid penetration of chloride ions as the drying ratio increases; however, they showed relatively high surface chloride concentration, ranged from 1.66 to $4.42 \%$ by weight of cement. The long-term exposure to the chloride environment may result in further accumulation of chloride ions at the surface, induced by salt crystallization by drying. Comparing the profile data at the time of corrosion initiation, $2 \mathrm{w} / 8 \mathrm{~d}$ and $5 \mathrm{w} / 5 \mathrm{~d}$ specimens show a similar amount of the total chloride content at the steel depth (Figure 5(d)). Since the cover depth of the specimen was $15 \mathrm{~mm}$, the CTL for $2 \mathrm{w} / 8 \mathrm{~d}$ and $5 \mathrm{w} / 5 \mathrm{~d}$ specimens is about $0.2 \%$ which is similar to the BS and ACI standards, while the CTL of $10 \mathrm{w}$ is about $0.3 \%$. 


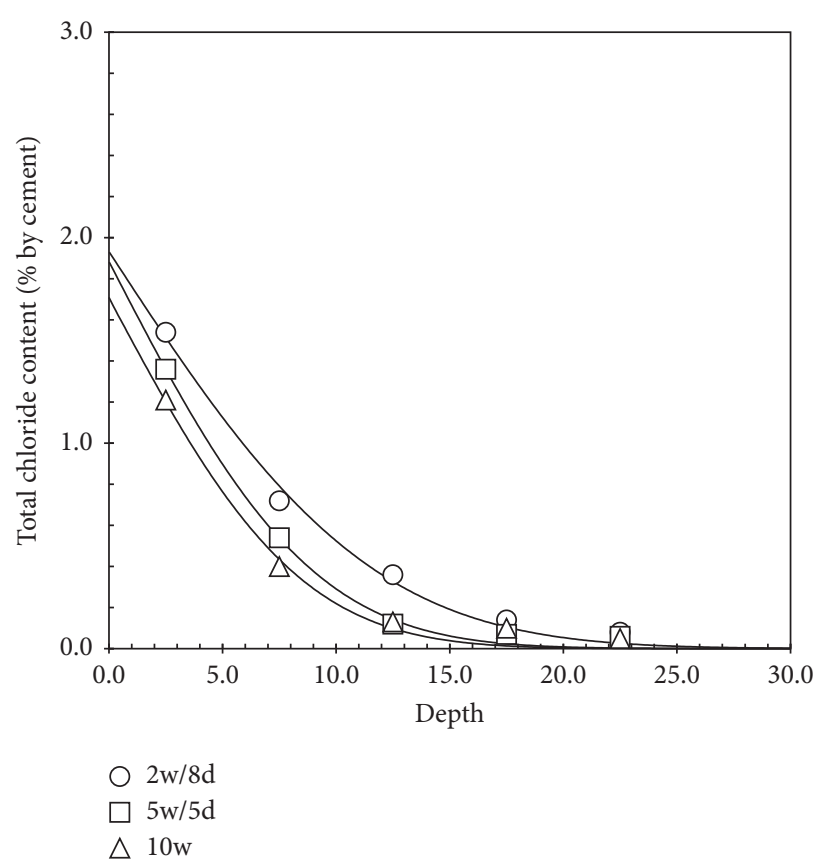

(a)

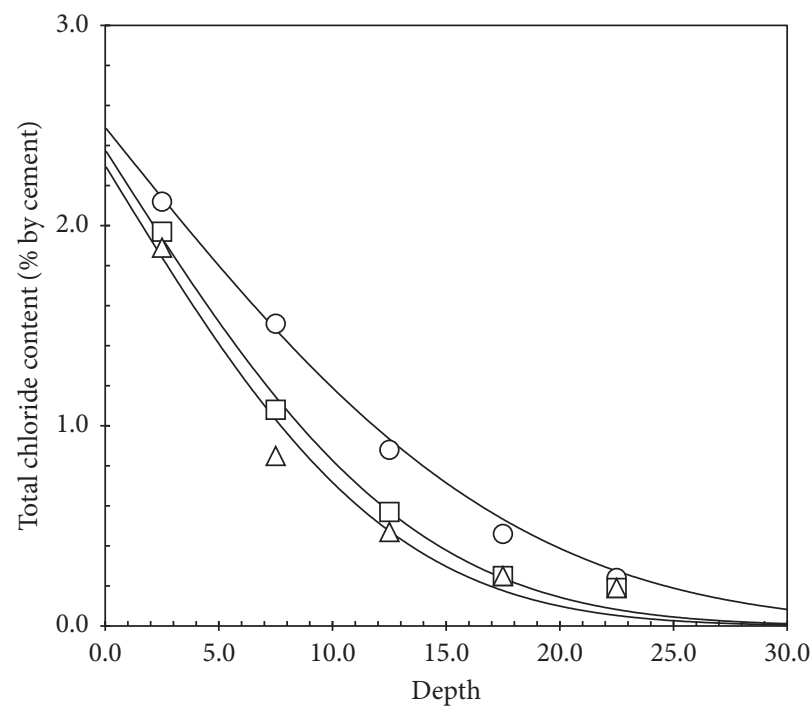

$$
\begin{aligned}
& \bigcirc 2 \mathrm{w} / 8 \mathrm{~d} \\
& \square 5 \mathrm{w} / 5 \mathrm{~d} \\
& \triangle 10 \mathrm{w}
\end{aligned}
$$

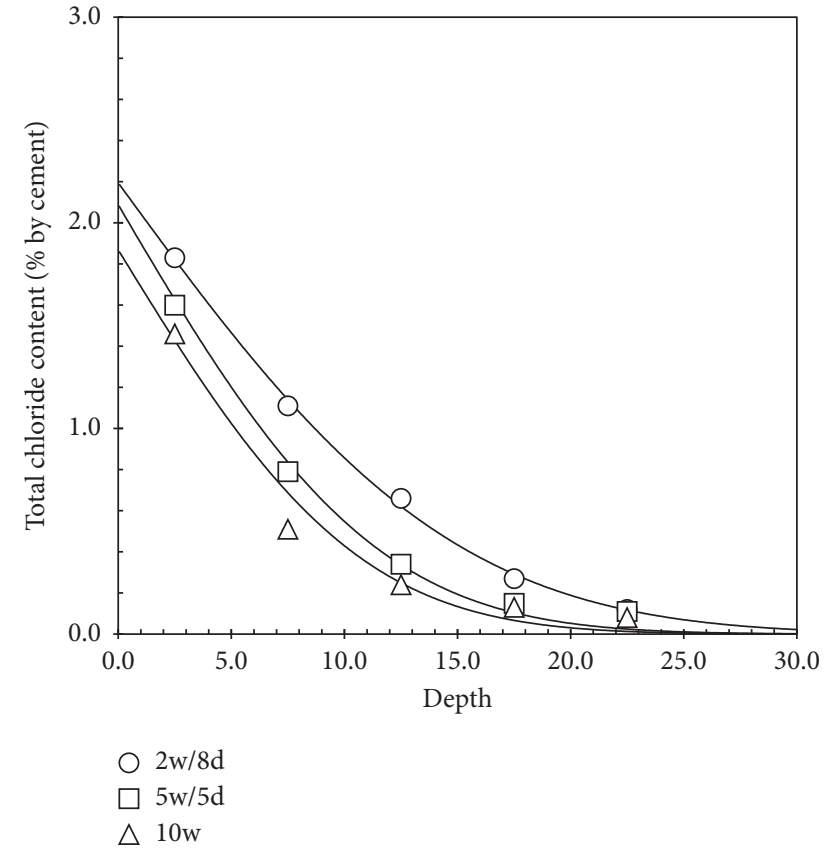

(b)

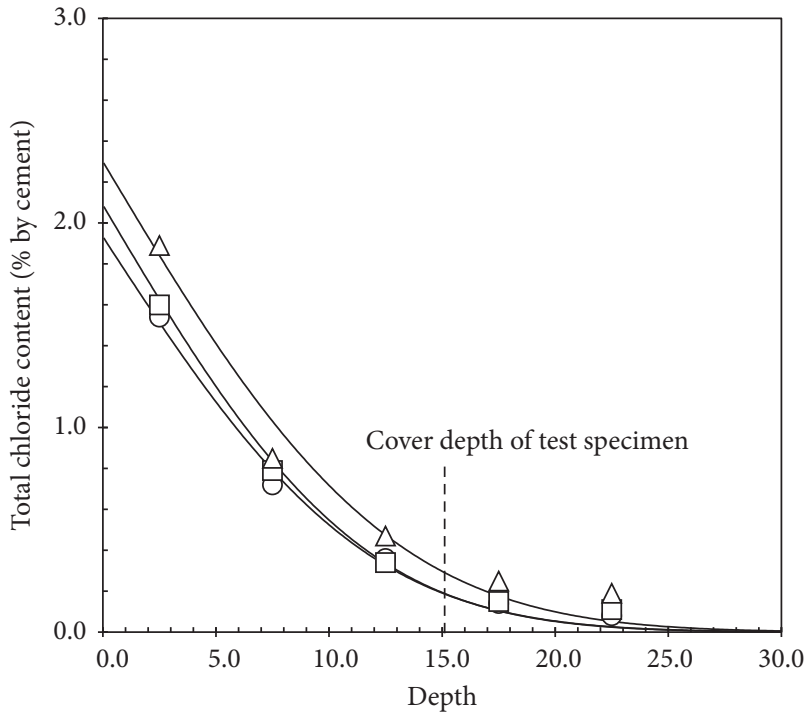

$$
\begin{aligned}
& \bigcirc 2 \mathrm{w} / 8 \mathrm{~d} \\
& \square 5 \mathrm{w} / 5 \mathrm{~d} \\
& \triangle 10 \mathrm{w}
\end{aligned}
$$

(c)

(d)

Figure 5: Chloride profile results at (a) 40, (b) 90, and (c) 160 days with different exposure condition, and (d) at the time when corrosion initiated.

TABLE 1: Surface chloride and apparent chloride diffusion coefficients at 40, 90, and 160 days.

\begin{tabular}{lcccccc}
\hline \multirow{2}{*}{ Exposure condition } & \multicolumn{2}{c}{40 days } & \multicolumn{2}{c}{90 days } & \multicolumn{2}{c}{160 days } \\
& $C_{\mathrm{s}}(\%)$ & $D\left(\mathrm{~m}^{2} / \mathrm{s}\right)$ & $C_{\mathrm{s}}(\%)$ & $D\left(\mathrm{~m}^{2} / \mathrm{s}\right)$ & $C_{\mathrm{s}}(\%)$ & $2.72^{*}$ \\
\hline $2 \mathrm{w} / 8 \mathrm{~d}$ & 1.93 & $11.19^{*}$ & 2.19 & $5.12^{*}$ & $2.18^{*}$ \\
$5 \mathrm{w} / 5 \mathrm{~d}$ & 1.88 & $7.13^{*}$ & 2.09 & $4.46^{*}$ & 2.38 & $4.10^{*}$ \\
$10 \mathrm{w}$ & 1.71 & $6.26^{*}$ & 1.87 & $3.54^{*}$ \\
\hline
\end{tabular}

${ }^{*} \times 10^{-12}$. 
3.3. Life Cycle Prediction. In service life prediction, although the CTL of external chloride is lower than that of internal, it is difficult to determine the corrosion risk according to the chloride source. External chloride takes time to penetrate until steel depth, and increase of cover depth can delay it. On the other hand, internal chloride has a risk of rebar corrosion immediately after casting because it is always present nearby the steel. In addition, quantification of the total chloride content which exists in mixing materials (e.g., water, sand, and gravel) is knotty. Accordingly, in this paper, the chloride penetration and service life prediction were conducted only for external chloride.

To predict the chloride penetration, subsequently to predict the service life, time dependency of chloride transport should be considered [25]. Generally, the chloride transport in concrete was extrapolated based on Fick's law of one-dimensional diffusion with constant diffusivity. It contains some basic assumptions of that (1) the concrete is exposed on the constant chloride concentration and (2) the pore matrix is homogeneous; that is, it shows an identical diffusivity throughout the concrete at the same time. However, from Tang and Nilsson [26], chloride diffusion coefficients at early age decreased with time and they mathematically expressed the reduction, taking into account the time dependency, as follows:

$$
\begin{aligned}
D(t) & =D_{\text {ref }}\left(\frac{t_{\text {ref }}}{t}\right)^{m}, \\
m & =\frac{\ln (D(t))}{\ln \left(D_{\text {ref }}\right)\left(t_{\text {ref }} / t\right)},
\end{aligned}
$$

where $m$ is the age factor and $D_{\text {ref }}$ and $D(t)$ are chloride diffusion coefficients at the exposure time of $t_{\text {ref }}$ and $t$, respectively. Based on the experimental results, the apparent diffusion coefficient at 40 days was used as $D_{\text {ref }}$, and $m$ was calculated by (3), corresponding to the values of 0.3208 , 0.3473 , and 0.3468 for $2 \mathrm{w} / 8 \mathrm{~d}, 5 \mathrm{w} / 5 \mathrm{~d}$, and $10 \mathrm{w}$, respectively. In the previous studies $[27,28]$ and life cycle prediction programs (Life 365, DuraCrete 2000), the recommended value of $m$ varies from 0.2 to 0.55 . Therefore, the obtained values of $m$ were considered to be an appropriate value. Using these age factors, the chloride transportation was predicted with time-dependent diffusion coefficient, as shown in Figure 6. For the boundary condition of the prediction model, the chloride concentration at the exposed surface was set to $1.0 \mathrm{M}$ and the cover depth was $50 \mathrm{~mm}$. It was evident that a decrease in drying ratio increases the required time of chloride transport to reach up to CTL at the specified cover depth. The service life was predicted as 2.35 , 4.73 , and 13.1 years for $2 \mathrm{w} / 8 \mathrm{~d}, 5 \mathrm{w} / 5 \mathrm{~d}$, and $10 \mathrm{w}$, respectively. In particular, the predicted service life of $2 \mathrm{w} / 8 \mathrm{~d}$ and $10 \mathrm{w}$ was clearly different because the CTL of $2 \mathrm{w} / 8 \mathrm{~d}$ is lower than $10 \mathrm{w}$ and the chloride transport rate of $2 \mathrm{w} / 8 \mathrm{~d}$ is basically high. Thus, it is evident that the corrosion initiation is likely to be promoted in the marine structures exposed to the high drying ratio condition, that is, high tide level. Furthermore, reminding that an increase in the drying ratio increases the corrosion rate after corrosion initiation, it is expected that the deterioration of the structure, induced by chloride

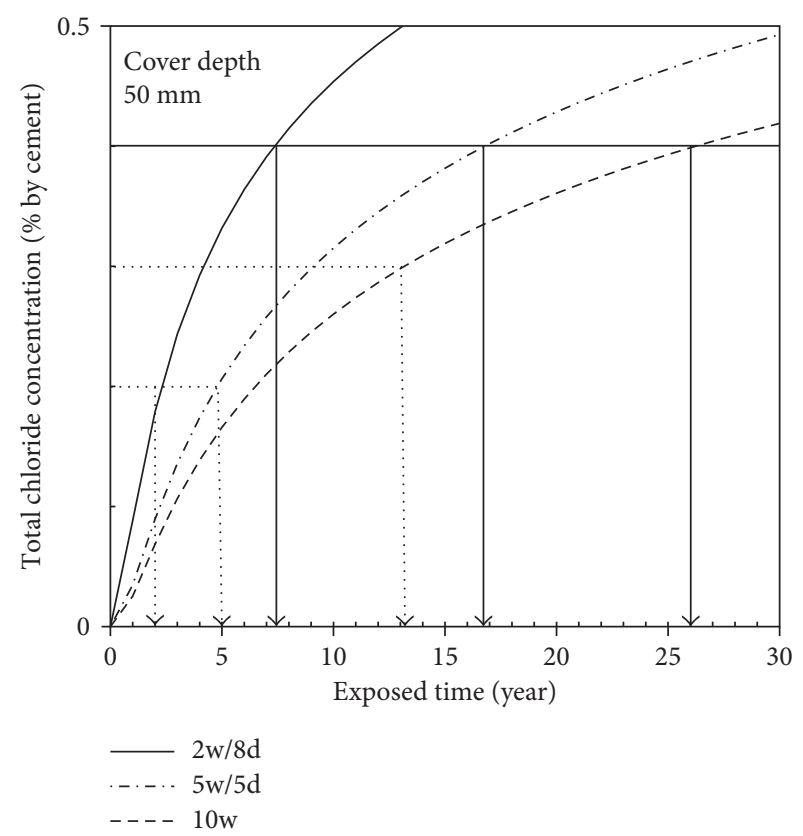

Figure 6: Prediction of chloride concentration with time (cover depth: $50 \mathrm{~mm}$ ).

propagation, will be accelerated. When it comes to a conservative value for the CTL (i.e., 0.4\%), the predicted corrosion-free life could be enormously increased up to 13.0, 16.8 , and 26.1 years for $2 \mathrm{w} / 8 \mathrm{~d}, 5 \mathrm{w} / 5 \mathrm{~d}$, and $10 \mathrm{w}$, respectively. It suggests that the CTL would be a crucial factor to govern the service life of concrete structures exposed to a salt environment. The difference in the CTL in terms of the corrosion resistance from experiment and real structures would arise from the reactivity in the cathodic region on the steel surface. In wet and dry cyclic environments (i.e., in the present study), oxygen and water could percolate the concrete to the depth of the steel, depending on the duration of exposure to the atmospheric condition. Thus, cathodic reaction could accompany the anodic process on the steel surface, leading to accelerate the corrosion process. In turn, the corrosiveness would be rapidly developed, producing the lower CTL. However, in the real structure, the penetrability of cathodic agents may be limited, in particular, to the depth of the steel: the cover depth usually exceeds $50-100 \mathrm{~mm}$ in a marine environment, and thus, the access of oxygen and water is restricted to the steel. Substantially, the corrosiveness would be retarded by limited cathodic reaction on the steel surface, thereby producing the increased corrosion resistance in terms of the higher CTL.

\section{Conclusion}

In the present study, the corrosion risk of reinforced concrete structure arising from internal chloride and external chloride was evaluated. The corrosion rate was monitored, and the chloride transport was analyzed to determine the CTL according to the chloride source. In addition, in the case of external chloride, the service life prediction was conducted with different exposure conditions. The conclusions derived from the experimental works are as follows: 
(1) As the results of the monitoring of the galvanic currents, the corrosion initiation was greatly affected by the exposure condition. The wet/dry condition accelerates the onset of corrosion than the totally wet condition, presumably due to the increased penetration of oxygen and chloride.

(2) The measurement of LPR gave an informative data to decide the CTL depending on the chloride source. Internal chloride showed higher CTL than external chloride, which is thought to be caused by the reduction of the amount of free chloride, participating in the corrosion process, by chloride binding in the initial hydration stage.

(3) The dry ratio of the exposure condition increases the corrosion rate after the initiation of corrosion. Accordingly, it is expected that the corrosion propagation will be promoted in marine structure exposed to high tide level.

(4) Consequently, a dramatical decrease of service life was predicted in structures exposed to high tide level. Also, since the corrosion propagation rate is high, accelerated defects of structural behavior are expected.

\section{Conflicts of Interest}

The authors declare that they have no conflicts of interest.

\section{Acknowledgments}

This research was supported by the research fund of Hanyang University (HY-2013-N).

\section{References}

[1] P. Schiessl and M. Raupach, "Influence of concrete composition and microclimate on the critical chloride content in concrete," in Corrosion of Reinforcement in Concrete, C. L. Page, K. W. J. Treadaway, and P. B. Bamforth, Eds., pp. 49-58, Elsevier Applied Science, London, UK, 1990.

[2] K. Y. Ann and H. W. Song, "Chloride threshold level for corrosion of steel in concrete," Corrosion Science, vol. 49, no. 11, pp. 4113-4133, 2007.

[3] R. D. Hooton, M. R. Geiker, and E. C. Bentz, "Effects of curing on chloride ingress and implications on service life," $A C I$ Material Journal, vol. 99, no. 2, pp. 201-206, 2002.

[4] M. Funahashi, "Predicting corrosion free service life of a concrete structure in a chloride environment," ACI Material Journal, vol. 87, no. 6, pp. 581-587, 1990.

[5] M. Thomas, "Chloride threshold in marine concrete," Cement and Concrete Research, vol. 26, no. 4, pp. 513-519, 1996.

[6] P. Sandberg, Chloride Initiated Reinforcement Corrosion in Marine Concrete, Lund Institute of Technology, Dissertation (Report TVBM-1015), Lund, Sweden, 1998.

[7] B. Elsener and H. Böhni, "Corrosion of steel in mortar studied by impedance measurements," Materials Science Forum, vol. 8, pp. 363-372, 1986.

[8] B. B. Hope and A. K. C. Ip, "Chloride corrosion threshold in concrete," Materials Journal, vol. 84, no. 4, pp. 306-314, 1987.

[9] B. H. Oh, S. Y. Jang, and Y. S. Shin, "Experimental investigation on the threshold chloride concentration for corrosion initiation in reinforced concrete structures," Magazine of Concrete Research, vol. 55, no. 2, pp. 117-124, 2003.
[10] K. Pettersson, Corrosion Threshold Value and Corrosion Rate in Reinforced Concrete, CBI Report 2:92, Swedish Cement and Concrete Research Institute, Stockholm, Sweden, 1992.

[11] C. Alonso, M. Castellote, and C. Andrade, "Chloride threshold dependence of pitting potential of reinforcements," Electrochimica Acta, vol. 47, no. 21, pp. 3469-3481, 2002.

[12] W. Morris, A. Vico, and M. Vazquez, "Chloride induced corrosion of reinforcing steel evaluated by concrete resistivity measurements," Electrochemica Acta, vol. 49, no. 25, pp. 4447-4453, 2004.

[13] C. Andrade and J. A. Gonzalez, "Quantitative measurements of corrosion rate of reinforcing steels embedded in concrete using polarization resistance measurements," Werkstoffe und Korrosion, vol. 29, no. 8, pp. 515-519, 1978.

[14] C. Alonso, C. Andrade, M. Castellote, and P. Castro, "Chloride threshold values to depassivate reinforcing bars embedded in a standardized OPC mortar," Cement and Concrete Research, vol. 30, no. 7, pp. 1047-1055, 2000.

[15] R. B. Polder and W. H. A. Peelen, "Characterisation of chloride transport and reinforcement corrosion in concrete under cyclic wetting and drying electrical resistivity," Cement and Concrete Composites, vol. 24, no. 5, pp. 427-435, 2002.

[16] Y. Zhang and W. L. Jin, "Distribution of chloride accumulation in marine tidal zone along altitude," ACI Materials Journal, vol. 108, no. 5, pp. 467-475, 2011.

[17] British Standards Institution, Part 1: Structural Use of Concrete-Code of Practice for Design and Construction, BS 8110, BSI, London, UK, 1985.

[18] American Concrete Institute, Corrosion of Metals in Concrete, Manual of Concrete Practice, Part 3, ACI Committee 222, ACI, Detroit, MI, USA, 1994.

[19] C. Arya, N. R. Buenfeld, and J. B. Newman, "Factors influencing chloride binding in concrete," Cement and Concrete Research, vol. 20, no. 2, pp. 291-300, 1990.

[20] O. Wowra and M. J. Setzer, "Sorption of chlorides on hydrated cements and C3S pastes," in Frost Resistance of Concrete, M. J. Setzer and R. Auberg, Eds., pp. 147-153, E \& FN Spon, London, UK, 1997.

[21] P. Vassie, "Reinforcement corrosion and the durability of concrete bridges," Proceedings of the Institution of Civil Engineers, vol. 76, no. 3, pp. 713-723, 1984.

[22] P. B. Bamforth, "The derivation of input data for modelling chloride ingress from eight-year UK coastal exposure trials," Magazine of Concrete Research, vol. 51, no. 2, pp. 87-96, 1999.

[23] K. C. Liam, S. K. Roy, and D. O. Northwood, "Chloride ingress measurements and corrosion potential mapping study of a 24year-old reinforced concrete jetty structure in a tropical marine environment," Magazine of Concrete Research, vol. 44, no. 160, pp. 205-215, 1992.

[24] TWRL, Marine Durability Survey of the Tongue Sand Tower. Concrete in the Oceans, Tech. Rep. 5, Cement and Concrete Association, London, UK, 1980.

[25] S. W. Pack, M. S. Jung, H. W. Song, S. H. Kim, and K. Y. Ann, "Prediction of time dependent chloride transport in concrete structures exposed to a marine environment," Cement and Concrete Research, vol. 40, no. 2, pp. 302-312, 2010.

[26] L. Tang and L. O. Nilsson, "Chloride diffusivity in high strength concrete at different ages," Nordic Concrete Research Publication, vol. 11, pp. 162-171, 1992.

[27] L. Wu, W. Li, and X. Yu, "Time-dependent chloride penetration in concrete in marine environments," Construction and Building Materials, vol. 152, pp. 406-413, 2017.

[28] O. E. Gjorv, "Durability of concrete structures," Arabian Journal of Science and Engineering, vol. 36, no. 2, pp. 151-172, 2011. 


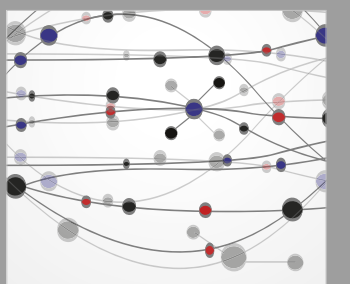

The Scientific World Journal
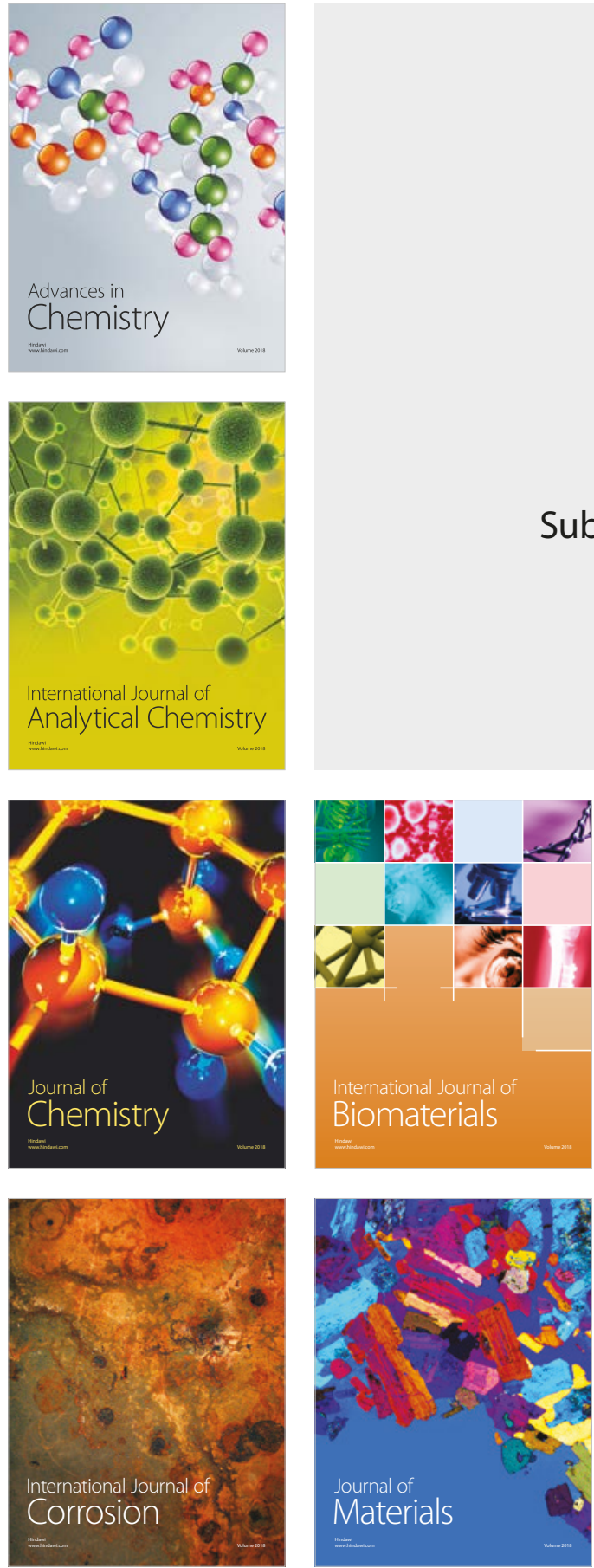

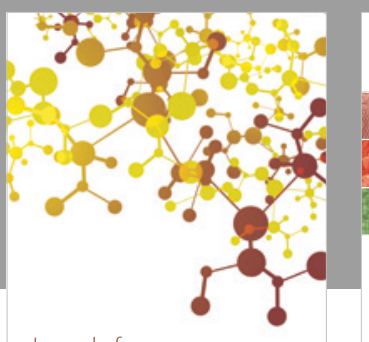

Journal of

Applied Chemistry
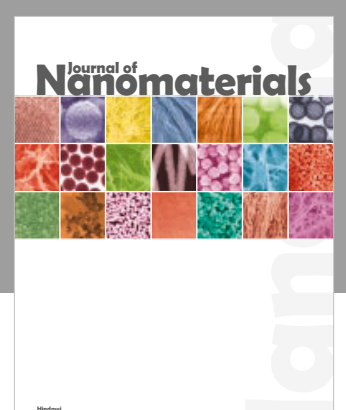

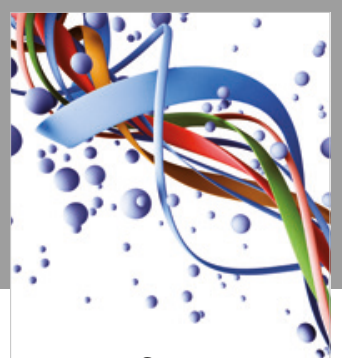

Scientifica

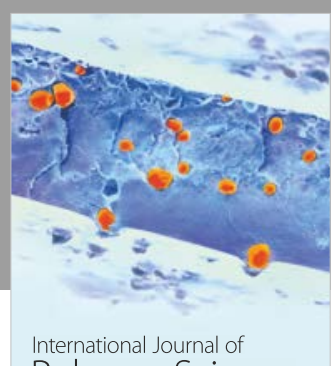

Polymer Science

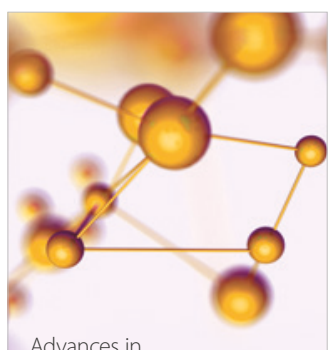

Physical Chemistry
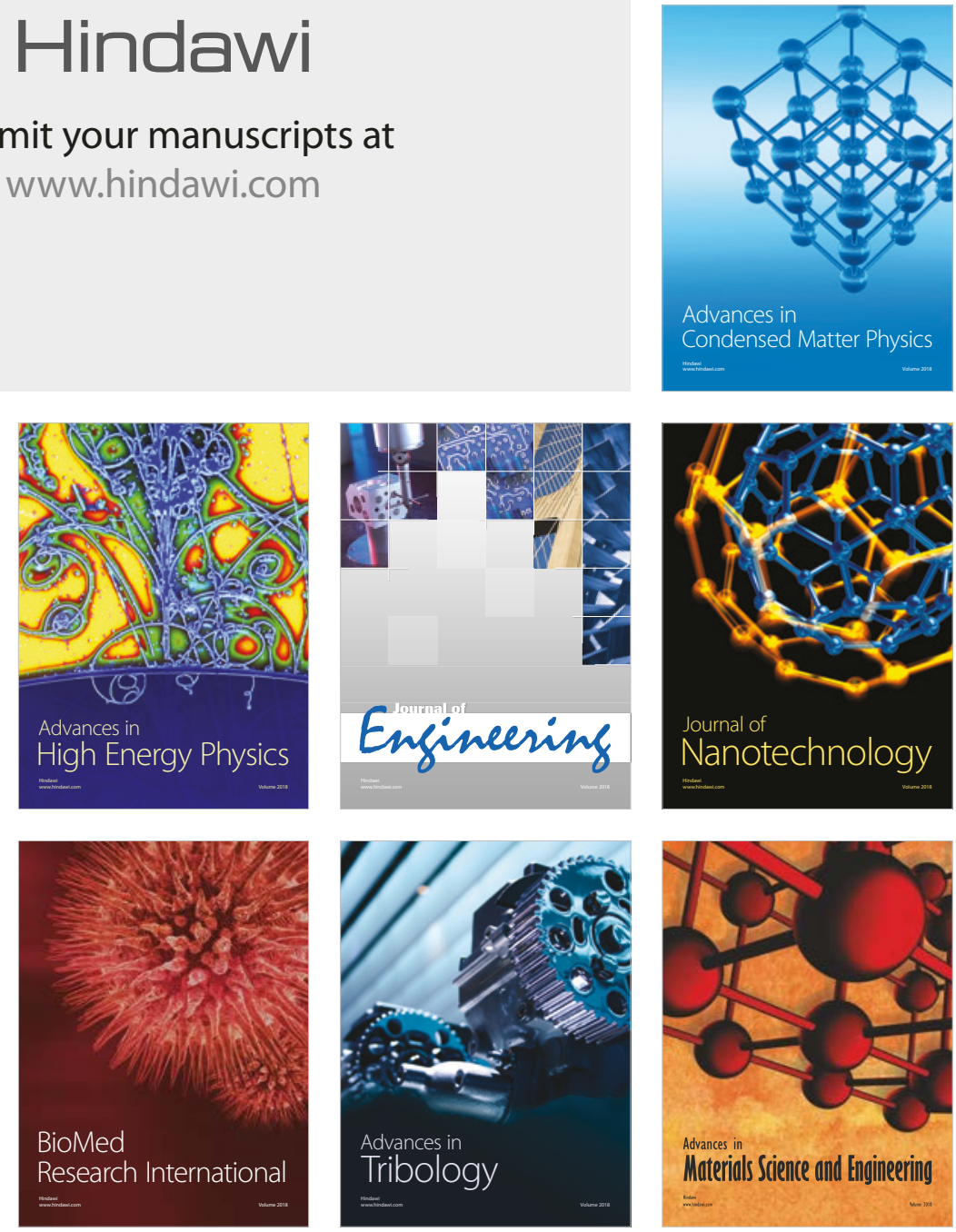